\title{
FOREWORD
}

This Glossary is designed for use by undergraduate students as an initial source of information. It does not replace any of the existing excellent Sachwörterbücher. It is however useful in that it aims specifically to provide a ready and inexpensive source of reference for English-speaking students and for scholars of other disciplines with only a limited knowledge of German, who are confronted with technical terms from German literary scholarship.

The Glossary contains 1379 entries, and approximately 250 of these have been dealt with in the form of short explanatory essays, contributed by 62 scholars from New Zealand, Australia, England Wales, Canada and the United States. The authors of these contributions are indicated by their initials. Entries without initials are the responsibility of the editors.

In order to keep the size and the cost of the Glossary within bounds appropriate to undergraduate students, it has been necessary to make a selection of the most commonly encountered literary terms. Bearing in mind the needs of Englishspeaking students we have excluded terms which are synonymous in German and English, and also literary terms of relevance only to non-German literatures; we have tried to concentrate on important or typical German literary terms, or terms which are used in different ways in English and German, e.g.: Romantik, Fiktion, Literaturkritik, Vers etc., and on certain terms of a technical nature, such as metrical terms, or terms derived from Greek and Latin, such as the names of the Muses, which are the same in German and English, but are largely unknown to present-day students. Any selection is of course arbitrary and can be criticized for sins of omission and commission. Editors faced with the need to select can only adhere to certain guiding principles and use their discretion. We have deemed it useful to students to give dates of birth and death of writers, where no other indication of the age in which they lived is given in the text. Dates given for literary works are the dates of first publication, whenever these can be ascertained.

The technical production of the Glossary has been entirely from the resources of the University of Otago. The Editors would however like to record their gratitude for the indispensible financial support of the German Embassy in Wellington and the Goethe Institute, Wellington. Their thanks are also due to many individuals, especially to Fiona Kennedy for their work in compilation and checking, to Joyce Walker for typing the manuscript, to Lyn Knarston and Peter Scott of the Medical Illustrations Unit for type-setting and design, to J. T. Robertson of the University Printery and to A. W. G. van Egmond of the University Bindery.

E.W.H.

A.O. 


\section{FOREWORD TO THE SECOND EDITION}

As the first edition is sold out and the demand for the Glossary is still growing, it was imperative to produce a second edition. This new edition contains approximately a further 100 entries, and many revisions; it contains 1470 entries contributed by 66 scholars from New Zealand, Australia, England, Scotland, Wales, Canada and the United States. As in the first edition, the authors of these contributions are indicated by their initials, while entries without initials are the responsibility of the editors. We have deviated slightly from the selection criteria of the first edition and have added terms suggested by reviewers, reader and users of the book.

The technical production has been partly from the resources of the University of Otago, partly commercial.

The editors would like to thank Natalie Blackburn for her valuable assistance.

E.W.H.

A.0. 